\title{
Solid pseudopapillary neoplasms-experience from a tertiary care centre
}

\author{
Chin thakindi M. ${ }^{1}$, Kyyoda P. ${ }^{2}$, Jyothi prakasham V.K. ${ }^{3}$, Reddy R.P. ${ }^{4}$ \\ ${ }^{1}$ Dr. Madhusudhan Chinthakindi, Associate Professor, ${ }^{2}$ Dr. Kyyoda Prashanth, Registrar, above two authors are affiliated \\ with Department of Surgical Gastroenterology, Osmania Medical College/ Hospital, Hyderabad, ${ }^{3}$ Dr. Jyothiprakasham \\ Vinod Kumar, Consultant, Maxcure Hospitals, Secretariat Branch, Hyderabad, ${ }^{4}$ Dr. Ramalingam Pratap Reddy, \\ Profes sor, Depart ment of Surg ical Gastroenterology, Osmania Medical College/ Hospital, Hyderabad, India.
}

Corres ponding Author: Dr.Madhusudhan Chinthakindi, Associate Professor, Department of Surgical Gastroenterology, Osmania Medical College /Hospital, Hyderabad. Email: madhuchinthakindhi@rediffmail.com

\begin{abstract}
Introduction: Solid pseudopapillary neoplasms (SPN/FRANTZ TUMOUR) of the pancreas are rare neoplasms of low grade malignant potential which were first described in 1959 by Frantz. These account for $0.13-2.7 \%$ of pancreatic neoplasms and approximately $13 \%$ of surgically resected cystic lesions of the pancreas. We present our experience with these rare tumors. Methods: Total 406 patients with pancreatic tumours were admitted in our department during the 10 year period (Between 2007 and 2017) were reviewed, only 18 were diagnosed as having SPN (4.4\%). Clinicopathological details, intervention done and follow up of all the cases were studied and reported here. Results: 17 patients were wo man and1was Man with median age of 23 years (range 11 to 54 years). The tumor size ranged from 3.8 to $17 \mathrm{~cm}$ (average $6.4 \mathrm{~cm}$ ). 12 patients presented with pain in the abdomen, 4 presented with a painless mass, 1 was detected incidentally and1presented with Malena. In 7 patients the tumor was in the pancreatic head, in 3 it was in the neck, and in the remaining 8 it is in the body and tail. CECT was done in all cases. 8 patients underwent Distal pancreatectomy with splenectomy, 1 underwent a PPPD, 6 patients required classical Whipple operation. 3 underwent central pancreatectomy. Immuno histochemistry showed positivity for beta catenin, vimentin, PR receptor and chromogranin negativity. All 18 patients were free of disease in a median follow- up period of 32 months (range 6-84) months. Conclusion: SPNs are rare neoplasms, typically affecting young women without notable symptoms, with a low malignant potential but excellent prognosis. Radical surgical resection with clear margins is the treatment of choice.
\end{abstract}

Key words: Female, Pancreas, Solid pseudopapillary neoplasm of pancreas, Solid-cystic Tu mour.

\section{Introduction}

Solid pseudopapillary neoplasms (SPN/FRANTZ TUMOUR) of the pancreas are rare neoplasms of low grade malignant potential which were first described in 1959 by Frantz. These account for $0.13-2.7 \%$ of all pancreatic tumors and predominantly affects young women occurs in the second or third decades of life $[1,2]$.

Earlier this tumor was called by various names including 'solid cystic tumor', 'papillary cystic tumor', 'papillary epithelial neoplasia', 'solid and papillary epithelial neoplasia', 'papillary epithelial tumor' and 'Frantz's tumor', 'solid and papillary tumor', 'solidcysticpapillary epithelial neoplasm', 'benign or

Manuscript received: $17^{\text {th }}$ January 2018

Reviewed: $27^{\text {th }}$ January 2018

Author Corrected: $3^{\text {rd }}$ February 2018

Accepted for Publication $8^{\text {th }}$ February 2018 malignant papillary tumor of the pancreas'[3]. In 1996 WHO coined its current terminology Solid pseudopapillary tumor in the International classification of the tumours of exocrine pancreas [3]. These tumours have a long asymptomatic period and are usually detected when they have grown to a large size [4-8].

Abdominal mass is the most common presenting symptom, with dyspepsia, early satiety, nausea, or vomiting being less common presenting symptoms. Up to $20 \%$ of patients are asymptomatic with tumors identified either incidentally on imag ing or at operation for unrelated pathology [9.10]. Grossly, SPTs are identified as well demarcated, encapsulated tumors with extra pancreatic growth. Mixed solid and cystic components are evident with internal necrotic or hemorrhagic debris and lobulated, solid tissue at the 


\section{Original Research Article}

periphery. Characteristic radiographic features include the presence of an encapsulated mass with solid and cystic components on either CT scan or MRI, with MRI notably better for identification of certain tumor characteristics such as the presence of a capsule, hemorrhage or cystic degeneration [10]. SPT should be added to the differential diagnosis in any patient with a solid and partly cystic mass of the pancreas especially in females under 35 years of age. Surgical resection is the treatment of choice for affected patients and is associated with an overall good prognosis [11].

Radiological and pathological studies have revealed that the tumor is quite different from other pancreatic tumors. But the cell orig in of SPT and tumorigenes is are still enig matic Due to the paucity of the number of cases seen, the natural history of the disease is not fully understood. This study was undertaken to examine the clin ico-pathological characteristics of the disease and to evaluate the outcome of surgical intervention in a tertiary referral cancer center.

\section{Materials and Methods}

Place of study and type of study: A retrospective analysis of all patients diagnosed and treated for SPN in
Osmania General Hospital/ College, Hyderabad over the past 10 years (2007 to 2017) was carried out. The clin ico-pathological, radiological, operative and survival data were obtained and analysed.

A Contrast enhanced CT scan (CECT) of the abdomen was performed in all the patients and Immuno histochemistry was performed in $6 / 18$ patients. All the patients who underwent resection were followed up every 6 months. The investigations performed included routine blood investigations, chest X-ray, CA-19-9 level and either an ultrasound or a CT scan of the abdomen.

Inclusion criteria: Diagnosed, resected and histopathological confirmed cases of Solidpseudo papillary neoplasms of pancreas were included in this study. In all, 18 patients were identified.

Exclusion criteria: if Histopathology report doesn't show SPN were excluded from the study.

Statistical methods: Continuous data were expressed as median/range and analysed by Kruskal-Wallis test, and categorical variables were expressed as number/ percentage and analysed by chi-square test.

\section{Results}

Total 406 patients with pancreatic tumours were admitted in our department during the 10year period was reviewed, only 18 were diagnosed as having SPN (4.4\%).17 patients were wo man and 1patient was Man. The patients had median age of

Table-1: showing demographic status, clinical presentation, site of lesion, size and Type of surgery.

\begin{tabular}{|c|c|c|c|c|c|}
\hline S.No. & Age/sex & Symptoms & Site of lesion & $\begin{array}{c}\text { Maxi mum } \\
\text { Size (cm) }\end{array}$ & Type of surgery \\
\hline 1 & F/11 & Pain abdomen & Head & 4 & Whipples procedure \\
\hline 2 & F/19 & Pain abdomen & Neck & 4.6 & Central pancreatectomy \\
\hline 3 & F/21 & Lump abdomen & Body and tail & 10.8 & Dis tal pancreatectomy \\
\hline 4 & F/20 & Pain abdomen & Body and tail & 13.5 & Distal pancreatectomy \\
\hline 5 & F/26 & Pain abdomen & Body and tail & 6.8 & Distal pancreatectomy \\
\hline 6 & M/48 & Lump abdomen & Body and tail & 11.4 & Dis tal pancreatectomy \\
\hline 7 & F/20 & Pain abdomen & Head & 6.1 & Whipples procedure \\
\hline 8 & F/29 & Pain abdomen & Head & 8.6 & Whipples procedure \\
\hline 9 & F/35 & Pain abdomen & Neck & 3.8 & Central pancreatectomy \\
\hline 10 & F/36 & Pain abdomen & Body and tail & 6.7 & Distal pancreatectomy \\
\hline 11 & F/21 & Incidentaldetection & Neck & 7.6 & Central pancreatectomy \\
\hline 12 & F/25 & Pain abdomen & Body and tail & 9 & Distal pancreatectomy \\
\hline 13 & F/16 & lump abdomen & Head & 17 & Whipples procedure \\
\hline 14 & F/15 & Lump abdomen & Head & 10 & PPPD \\
\hline 15 & F/20 & Pain abdomen & Head & 5 & Whipples procedure \\
\hline 16 & F/34 & Anaemia, malena & Head & 6 & Whipples procedure \\
\hline 17 & F/42 & Pain abdomen & Body and tail & 6 & Distal pancreatectomy \\
\hline 18 & F/54 & Pain abdomen & Body and tail & 6 & Distal pancreatectomy \\
\hline & & & & & \\
\hline
\end{tabular}




\section{Original Research Article}

23 years (range 11 to 54 years). The tumour size ranged from 3.8 to $17 \mathrm{~cm}$ (average $6.4 \mathrm{~cm}$ ). Twelve patients presented with a dull aching pain in the abdomen. Four presented with a painless abdominal mass in the upper abdominal region. One patient was detected incidentally. One patient presented with Malena. In 7 patients the tumour was located in the pancreatic head, in 3 it was located in the neck, and in the remaining 8 patients it occurred in the body and tail [Table1].

CECT was done in all cases.13 patients showed a well-defined mass with heterogeneous attenuation with solid and cystic components with displacement of adjacent structures [Figure 1]. Of the 18 patients, five had heterogeneous enhancement with large non-enhancing central areas. Predominantly solid tumour in 2 cases is represented by hypodensity on CT scan. There was no biliary or pancreatic ductal upstream dilatation despite large size except in one case where tumour was $17 \mathrm{~cm}$ size with central hae morrhage.
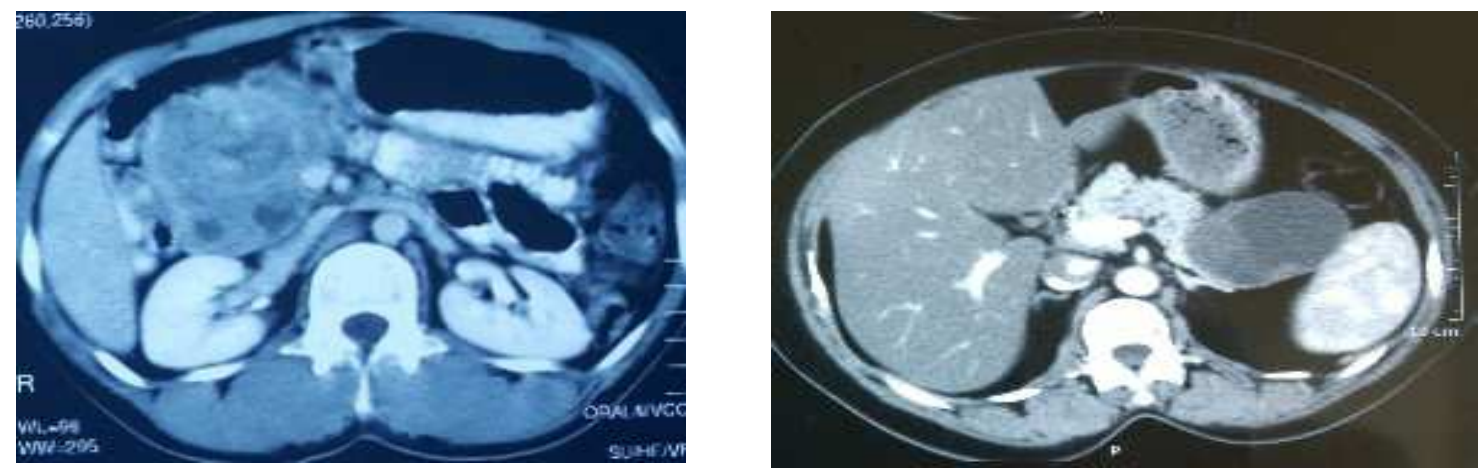

Figure-1: CECT Abdomen: well-defined mass with heterogeneous attenuation with solid and cystic components with displacement of adjacent structures in Head (A) and Tail (B).

In one case, the mass was significantly compressing Inferior Vena Cava (IVC) however there was no IVC invasion or thrombosis. In 4 cases, portal vein was compressed and displaced, and in one case the portal vein was partially encased for less than $180^{\circ}$ circumference. six patients had undergone a preoperative FNAC: in 4 patients the FNAC correctly diagnosed SPN.

Eight patients underwent distal pancreatectomy with splenectomy, one underwent a pylorus-preserving pancreatoduodenectomy, six patients required classical Whipple operation. 3 underwent central pancreatectomy. None of these patients had distant metastasis.

3 patients had biochemical (Grade A) Pancreatic leak, one had delayed gastric emptying and I patient had haemorrhage.

There was no postoperative mortality. All 18 patients were free of disease in a median follow- up period of 32 months (range 6 - 84) months. One patient developed diabetes and one patient had pancreatic exocrine deficiency.

The tumour was well encapsulated in all the cases [Figure 2(A)]. Tumours on cut section were predominantly solid, pale to deep brown or yellow, heterogenous cut-surface with haemorrhage and necrosis, and soft to firm in consistency [Figure 2(B)].
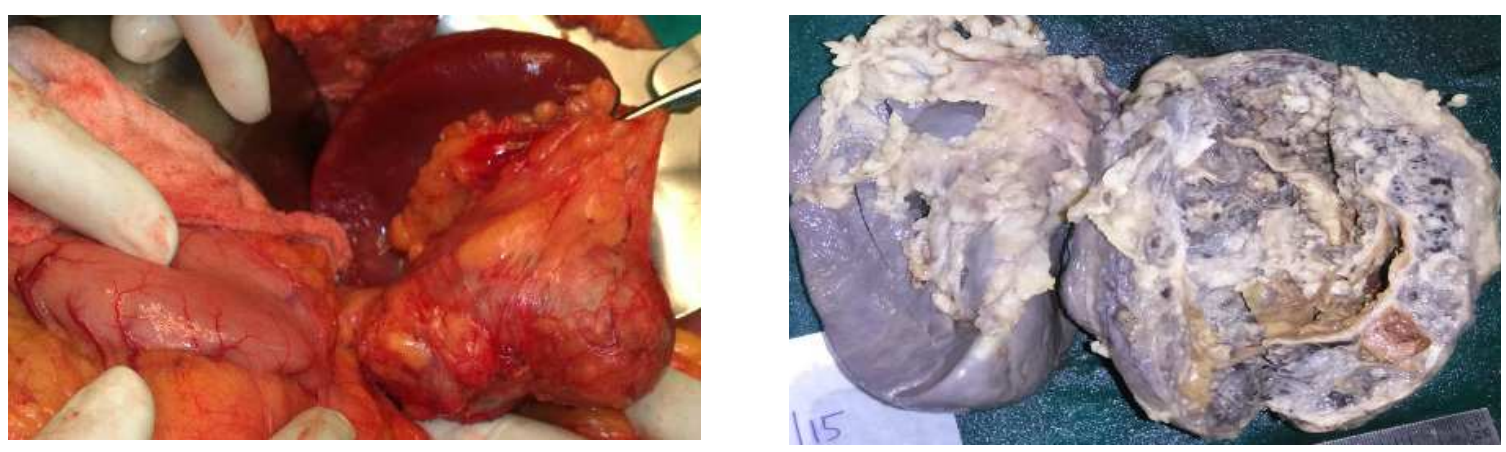

Figure-2:(A)well encapsulated tumour at Tail of pancreas. (B) Heterogenous cut-surface with haemorrhage and necrosis. 

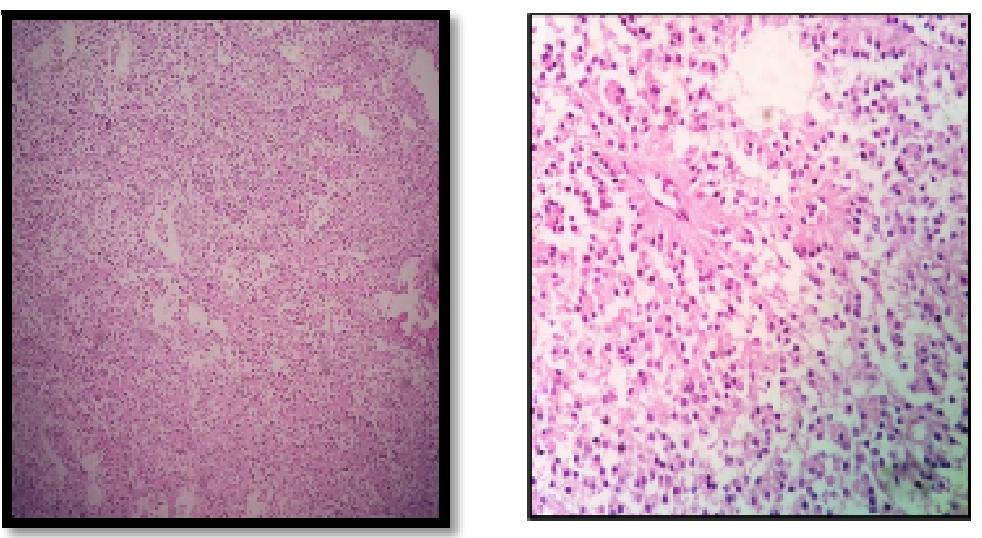

Original Research Article

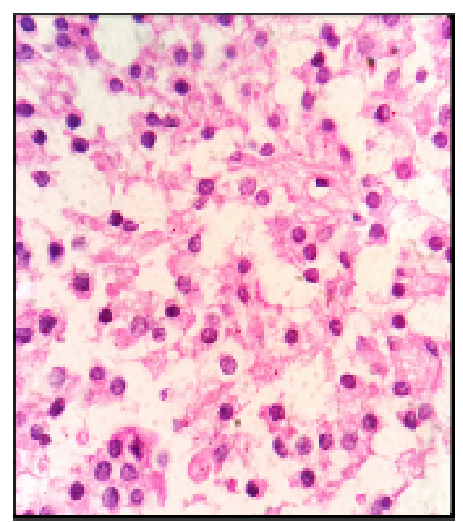

Figure-3: Histopathological examination: [Fig3 (A)] the tumour was composed of poorly cohesive uniform, cuboidal cells arranged in papillary pattern with thin fibrovascular core. [Fig 3(B)] The tumour cells had round to oval nuclei, fine chromatin and moderate amount of eosinophilic cytoplasm. [Fig 3(C)] The characteristic features like nuclear grooves were seen in all the cases.
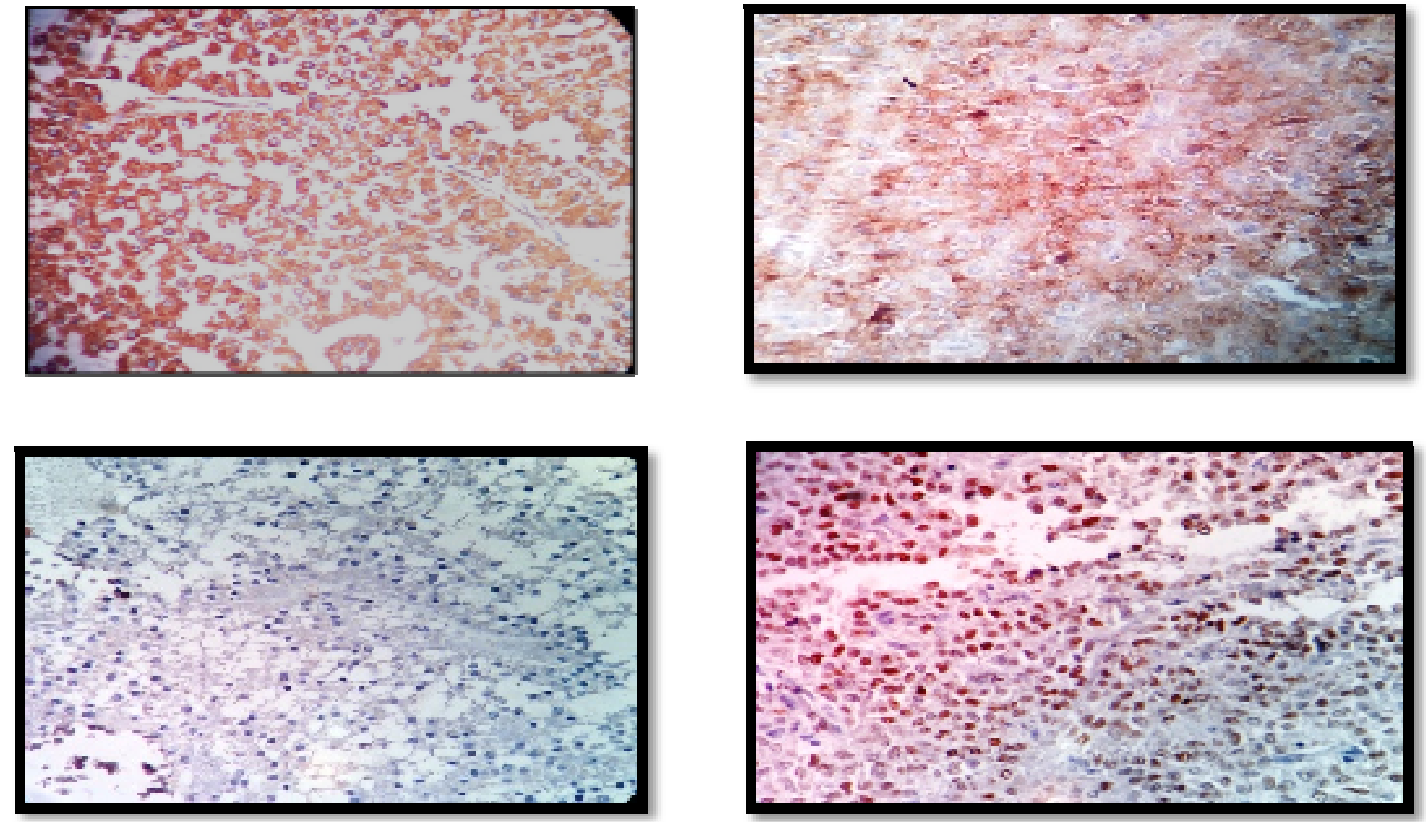

Figure-4: Immuno histochemistry: Tumour showed positivity for (A) Beta catenin, (B) vimentin, (C) PR receptor and (D) chro mogranin negativity

On histopathological examination, the tumour was composed of poorly cohesive uniform, cuboidal cells arranged in papillary pattern with thin fibrovascular core [Fig 3(A)]. The tumour cells had round to oval nuclei, fine chro matin and moderate amount of eosinophilic cytoplasm [Fig 3(B)]. The characteristic features like nuclear grooves were seen in all the cases (Fig 3(C)]. Stromal changes such as hyalinization and my xo id change in the core of the pseudo papillae. Few foci of haemorrhage and necrosis were also presentImmuno histochemistry was done 6cases. Tumour showed positivity for beta catenin, vimentin,PR receptor and chro mogranin negativity[Figure 4].

Histology did not reveal any feature of parenchymal, perineurial or angioinvasion and ly mph node involvement

\section{Discussion}

Solid pseudopapillary neoplasms are slow growing exocrine pancreatic tumours. This tumour was first described by Frantz VK in 1959 [1] as a "papillary tumour of the pancreas, benign or malignant" has a strong predilection for adult females with a male: female ratio of 1:10 [2]. seventeen cases in this study were female patients and similar exclusivity in females was reported by Patil TB et al., [12], and other studies have also consistently reported female preponderance $[13,14,15]$. It is more common in young non-Caucasian 
women, usually Asian and African-American women, between the second and third decades of life [16]. The median age of 23 years in the present study was concordant with the studies of Patil TB et al., and Mao C et al., [12,14].

Though, SPN can occur in any part of the pancreas, but tail of the pancreas appears to be the most common location. In this study, in $44.4 \%$ cases the tumour was located in tail of pancreas, as were $50 \%$ and $71 \%$ cases reported by Patil TB et al., and Huang HL et al., respectively $[12,13]$. The average size of $6.4 \mathrm{~cm}$ in the present study was close to the mean size of $5.8 \mathrm{~cm}$ reported by Wang DB et al., [13]. In the series by Paruchuri RK et al., all nine tu mours were encapsulated, and calcification was seen in two out of nine cases, similar to our experience [15].

CECT scan, ultrasonography (US) and Endosonography (EUS) have been used with variable success in diagnosing SPN. CT scan and EUS are more sensitive and specific and have shown more accuracy in diagnosing SPN [14,15].

Ultrasound shows a well-defined mass with solid and cystic components and increased vascularity. Contrast enhanced CT shows an encapsulated lesion with enhancing solid and non-enhancing cystic areas with some showing calcific foci. Haemorrhagic density may be seen within the lesion. On MDCT the SPN are encapsulated tumours, which are round to oval in shape and exhibit heterogeneous attenuation with peripheral iso- to hyperdense areas [15], similar to our study. Magnetic resonance imaging (MRI) can be diagnostic. Typically, a large, well-defined, encapsulated lesion with heterogeneous high or low signal intensity on T1weighted, heterogeneous high signal intensity on T2weighted, and early peripheral heterogeneous enhancement with progressive fill-in is found on gadolinium-enhanced dynamic MRI. These features help differentiate this rare tumour from other pancreatic neoplasms [16]. In our series, we relied on CT imaging for the pre- operative work-up.

Differential diagnosis for SPN would include pancreatic cancer and pancreatic Neuroendocrine Tumours (NET) [6]. Hyper attenuation of SPN compared to the surrounding pancreatic parenchyma on contrastenhanced triphasic CT images is due to SPN's rich blood supply, which helps to differentiate it from pancreatic neuroendocrine tumour. Also, unlike adenocarcinomas, secondary changes in the pancreas, such as dilatation of the upstream pancreatic duct or pancreatic parenchymal atrophy are usually not seen in SPN. MRI also helps in differentiate SPNs from islet cell tumours, in whom cystic components have moderately increased signal intensity on T1-weighted and increased signal intensity on $\mathrm{T} 2$-weighted images [6].

However, a young female having a well-circumscribed and capsulated tumour in the pancreas with haemorrhage and cystic changes, appearing as heterogeneously cystic central component and solid periphery, is in all likelihood SPN.

FNAC has been used for the preoperative cytological diagnosis of SPN [17,18]. The cytology specimen is usually highly cellular and is characterized by the presence of epithelioid cells that present singly or in aggregates containing fibrovascular cores. No evidence of pleomorphism or mitotic activity is seen in the cells. The most conclusive criterion for identification of SPN is the pseudopapillary arrangement with bland appearing tumour cells. EUS-guided FNAC has been reported, and this can help in correctly diagnosing SPN pre-operatively [19]. In the current series, 4/18 patients had a pre-operative percutaneous US-guided FNAC, and the diagnosis of SPN was made correctly in 3 patients. It is not necessary to have a tissue diagnos is pre-operatively, and surgery can be advised on the bas is of radio- logical imag ing.

On gross examination, SPN is a well encapsulated tumour. On cut section it shows solid and cystic areas with necrotic and haemorrhagic patches. Grossly SPN may mimic pancreatic pseudocyst or other cystic neoplasms. Yellow or haemorrhagic cut surface of SPN separates it from other cystic pancreatic neoplasms. Microscopically pancreatic pseudocyst lacks epithelial lining [3].

Solid pseudo-papillary neoplasms have specific histological features of SPN, such as pseudopapillae or structures resembling ependymal rosettes, but lacking acinar, cribriform and nested or trabecular pattern, which is seen in Acinar Cell Carcinoma (ACC) and NET, respectively. Nuclear grooving is a characteristic finding in SPN as opposed to salt and pepper chromatin of NET, and nuclear pleo morphism with single, central prominent nucleolus in ACC.

Immunopositivity for CD10, vimentin and $\beta$-catenin, and negativity to chromogranin A (characteristic in NET), and trypsin or chymotrypsin (characteristic of ACC), further confirms the diagnosis of SPN [3]. In our 


\section{Original Research Article}

series Immuno histochemistry was done 6 cases. Tumour showed positivity for beta catenin, vimentin, CD10, PR receptor and chromogranin negativity.

Marchegiani G et al., reviewed 131 cases and considered $16(12.2 \%)$ cases as malignant SPN due to the presence of at least two of the three histological features that is invasion of pancreatic parenchyma, perineural and or blood vessels. After a median of 62 months after surgery, only two (1.5\%) malignant SPNs had a recurrence [20]. In our series histology did not reveal any feature of parenchymal, perineurial or angioinvasion and ly mph node involvement.

No patient had recurrence during 32 moths of median follow-up period.SPN is a tumour of low-grade malignant potential [21]. The logical conclusion is that complete surgical excision is the best option for patients who have SPN. Thus, surgery should always be attempted in a suspected case of SPN even if it implies that major resections (like pancreaticoduodenectomy along with adjacent organ resection) have to be performed. A local recurrence rate of $6.2 \%$ is reported in cases treated by radical surgical excision, and hepatic or Krukenberg-type distant metastases develop in 5.6\% of cases [22]. In our series, all the patients who underwent resection were disease-free on follow-up.

\section{Conclusions}

A high index of clinical suspicion is necessary to suspect and diagnose SPN. This diagnosis should be borne in mind when young female patients present with a well encapsulated pancreatic mass. CT scan and EUS are valuable pointers to the pre-operative diagnosis. Surgical excision offers the best chance for cure and should always be attempted irrespective of the magnitude of resection involved. Patients with SPN have an excellent prognosis after surgical excision. The important observation in this study is the vessel involvement/encasement is not seen, though lesions reaching up to $15 \mathrm{~cm}$ in size.

\section{Authors Contribution:}

1. Prepared the manuscript and performed all surgeries.

2. Helped in data collection and involved in patient care.

3. Helped in data analysis and statistical analysis. Assisted majority of surgeries.

4. Supervised the paper and involved in patient care of these patients.

Funding: Nil, Conflict of interest: None.

Permission of IRB: Yes

\section{References}

1. Papavramidis T, Papavramidis S. Solid pseudopapillary tumors of the pancreas: review of 718 patients reported in English literature. J Am Coll Surg. 2005 Jun; 200(6):965-72.

2. Kim CW, Han DJ, Kim J, Kim YH, Park JB, Kim SC. Solid pseudopapillary tumor of the pancreas: can malignancy be predicted? Surgery. 2011 May; 149(5): 625-34. doi: 10.1016/j.surg.2010.11.005.

3. Kloppel G., Solcia E., Longnecker D.S., Capella C., Sobin L.H. Histological typing of tumors of the exocrine pancreas. World Health Organization International Histological Classification of Tumours; Berlin, Heidelberg, New York: Springer; 1996. (8452/1. ISBN [ISBN 3-540-60280-1])

4. Buetow PC, Buck JL, Pantongrag-Brown L, Beck KG, Ros PR, Adair CF. Solid and papillary epithelial neoplasm of the pancreas: imaging-pathologic correlation on 56 cases. Radiology. 1996 Jun;199 (3): 707-11.

5. Yu MH, Lee JY, Kim MA, Kim SH, Lee JM, Han JK, Choi BI. MR imaging features of small solid pseudopapillary tumors: retrospective differentiation from other small solid pancreatic tumors. AJR Am J Roentgenol. 2010 Dec;195(6):1324-32. doi: 10.2214/ AJR. 10.4452.

6. Baek JH, Lee JM, Kim SH, Kim SJ, Kim SH, Lee JY, Han JK, Choi BI. Small (<or=3 cm) solid pseudopapillary tumors of the pancreas at multiphasic mu ltidetector CT. Radiology. 2010 Oct;257(1):97-106. doi: 10.1148/radiol.10092089. Epub 2010 Jul 27.

7. El-Bahrawy MA, Rowan A, Horncastle D, Tomlinson I, Theis BA, Russell RC, Stamp G. Ecadherin/catenin complex status in solid pseudopapillary tumor of the pancreas. Am J Surg Pathol. 2008 Jan;32(1):1-7.

8. Cavard C, Audebourg A, Letourneur F, Audard V, Beuvon F, Cagnard N, Radenen B, Varlet P, VacherLavenu MC, Perret C, Terris B. Gene expression profiling provides insights into the pathways involved in solid pseudopapillary neoplasm of the pancreas. J Pathol. 2009 Jun;218(2):201-9. doi: 10.1002/path.2524.

9. Chen SQ, Zou SQ, Dai QB, Li H. Clinical analysis of solid-pseudopapillary tumor of the pancreas: report of 


\section{Original Research Article}

15 cases. Hepatobiliary Pancreat Dis Int. 2008 Apr; 7 (2):196-200.

10. Zhang H, Liang TB, Wang WL, Shen Y, Ren GP, Zheng SS. Diagnosis and treatment of solidpseudopapillary tumor of the pancreas. Hepatobiliary Pancreat Dis Int. 2006 Aug;5(3):454-8.

11. Tipton SG, Smyrk TC, Sarr MG, Thompson GB. Malignant potential of solid pseudopapillary neoplas $\mathrm{m}$ of the pancreas. Br J Surg. 2006 Jun;93(6):733-7.

12. Patil TB, Shrikhande SV, Kanhere HA, Saoji RR, Ramadwar MR, Shukla PJ. Solid pseudopapillary neoplasm of the pancreas: a single institution experience of 14 cases. HPB (Oxford). 2006;8(2):14850. doi: 10.1080/13651820510035721.

13. Huang HL, Shih SC, Chang WH, Wang TE, Chen MJ, Chan YJ. Solid-pseudopapillarytumor of the pancreas: clinicalexperience and literature review. World J Gastroenterol. 2005Mar7;11(9):1403-9.

14. Mao C, Guvendi M, Domenico DR, Kim K, Thomford NR, Howard JM. Papillary cystic and solid tumors of the pancreas: a pancreatic embryonic tumor? Studies of three cases and cumulative review of the world's literature. Surgery. 1995 Nov;118(5):821-8. Review.

15. Paruchuri RK, Kuruba HR, Pathapati D, Prayaga A. Role of preoperative multidetector computed tomography diagnos is of solid pseudopapillary tumours of the pancreas with postoperative surgical and histopathological correlation. West Afr J Radiol. 2017; 24 (1):45-51.

16. Coleman KM, Doherty MC, Bigler SA. Solidpseudopapillary tumor of the pancreas. Radiographics. 2003 Nov-Dec;23(6):1644-8.
17. Trivedi N, Sharma U, Das PM, Mittal MK, Talib VH. FNAC of papillary and solid epithelial neoplasm of pancreas--a case report. Indian J Pathol Microbiol. 1999 Jul; 42(3):369-72. PubMed PMID: 10862301

18. Naresh KN, Borges AM, Chinoy RF, Soman CS, Krishnamurthy SC. Solid and papillary epithelial neoplasm of the pancreas. Diagnosis by fine needle aspiration cytology in four cases. Acta Cytol. 1995 May-Jun;39(3):489-93.

19. Bardales RH, Centeno B, Mallery JS, Lai R, Pochapin M, Guiter G, Stanley MW. Endoscopic ultrasound-guided fine-needle aspiration cytology diagnosis of solid-pseudopapillary tumor of the pancreas: a rare neoplasm of elusive origin but characteristic cytomorphologic features. Am J Clin Pathol. 2004 May;121(5):654-62.

20. Marchegiani G, Andrianello S, Massignani M, Malleo G, Maggino L, Paiella S,Ferrone CR, Luch ini C, Scarpa A, Capelli P, Mino-Kenudson M, Lillemoe KD, BassiC, Castillo CF, Salvia R. Solid pseudopapillary tumors of the pancreas: Specific pathological features predict the likelihood of postoperative recurrence. J Surg Oncol. 2016 Oct;114(5):597-601. doi: 10.1002/jso. 24380. Epub 2016 Jul 29.

21. Klimstra DS, Wenig BM, Heffess CS. Solidpseudopapillary tumor of the pancreas: a typically cystic carcinoma of low malignant potential. Semin Diagn Pathol. 2000 Feb;17(1):66-80.

22. González-Cámpora R, Rios Martin JJ, Villar Rodriguez JL, Otal Salaverri C, Hevia Vazquez A, Valladolid JM, Portillo M, Galera Davidson H.Papillary cystic neoplasm of the pancreas with liver metastas is coexisting with thyroid papillary carcinoma. Arch Pathol Lab Med. 1995 Mar;119(3):268-73.

\section{How to cite this article?}

Chinthakindi M, Kyyoda P, Jyothiprakasham V.K, Reddy R.P. Solid pseudopapillary neoplasms-experience from a tertiary care centre. Int J Med Res Rev 2018;6 (02):71-77. doi:10.17511/ijmrr. 2018.102.02. 